\title{
DEMOCRACIA E CULTURA: UMA VISÃO NÃO CULTURALISTA*
}

\author{
ADAM PRZEWORSKI \\ JOSÉ ANTÔNIO CHEIBUB \\ FERNANDO LIMONGI
}

Será verdade que, para existir e perdurar, uma democracia precisa estar ancorada por uma "cultura democrática"? Se a resposta for positiva, quais são os padrões culturais específicos compatíveis com essa "cultura democrática" que, desse modo, favoreceriam ou prejudicariam a democracia?

Para uma das respostas possíveis, a visão "não culturalista", a cultura não exerceria poder causal para explicar a democracia. Um país não necessitaria de uma cultura democrática para estabelecer instituições democráticas nem para sustentá-las. Uma segunda resposta possível, o ponto de vista "culturalista fraco", sustenta que uma cultura democrática seria necessária para que uma democracia surja e se mantenha, mas a questão da compatibilidade dessa cultura democrática com as tradições de sociedades particulares seria controversa, pois essas tradições seriam maleáveis, sujeitas a serem inventadas e reinventadas. Desse modo, uma cultura democrática poderia florescer mesmo em ambientes culturais aparentemente hostis. Por último, a visão "culturalista forte" postula que algumas culturas seriam incompatíveis com a democracia. Em conseqüência, diferentes países deveriam buscar arranjos políticos distintos.

O objetivo do texto é discutir estas visões alternativas. Está em jogo saber se as instituições democráticas podem funcionar em todos os ambientes culturais ou se é preciso admitir que algumas culturas são compatíveis apenas com formas variadas de autoritarismo.

Trata-se de questão de difícil resposta. Ela está sujeita a conviç̧ões conflitantes arraigadas. As evidências requeridas não são fáceis de se obter. As disponíveis são insuficientes para esclarecer aspectos centrais desta pendência. Por isto, procuraremos apenas reconstruir essas posições rivais e citar

\footnotetext{
* "Culture and democracy". Texto revisto e adaptado para esta publicação por Fernando Limongi. Tradução de Gabriel Cohn.
} 
alguns fatos. Nossa conclusão geral é cética. Sustentamos que fatores econômicos e institucionais são suficientes para gerar uma explicação convincente da dinâmica das democracias sem que seja necessário recorrer à cultura. Constatamos empiricamente que os traços culturais mais óbvios, tais como a religião dominante, têm pouca importância para a emergência e a durabilidade de democracias. Disso decorre que, embora possa haver boas razões para esperar que culturas importem, o material empírico disponível provê pouco apoio para a concepção de que a democracia requer uma cultura democrática.

Iniciamos com uma breve história das concepções culturalistas e depois as analisamos mais sistematicamente. $\mathrm{O}$ aspecto central de nossa discussão é saber se a democracia pode emergir e persistir somente quando tem o apoio de determinados padrões culturais. São determinados aspectos da cultura necessários para a democracia, e, neste caso, quais e como? Desenvolvemos também uma explicação que dispensa a variável cultura e mostramos que ela é sustentada por certos fatos. Em seguida perguntamos se culturas específicas podem ser avaliadas como mais ou menos compatíveis com a democracia e examinamos empiricamente se essas culturas, grosseiramente definidas em termos de religiões nacionais dominantes, afetam a emergência e a sobrevivência de regimes democráticos. Um exame de algumas questões normativas encerra o artigo.

Será um tipo específico de cultura, de caráter "democrático", necessário para a emergência e persistência da democracia? Primeiro apresentamos um esboço histórico de respostas positivas a essa questão e introduzimos algumas distinções entre elas. Em seguida contrapomos essas respostas a uma concepção que dispensa a variável cultura para dar conta da emergência e sobrevivência da democracia.

\section{CONCEPÇÕES CULTURALISTAS}

Montesquieu, nas Lettres persanes (1721) e depois em De l'esprit des lois (1995 [1748]) foi o primeiro a sustentar que cada forma de governo requer a presença de determinados padrões culturais para permanecer e funcionar efetivamente ${ }^{1}$. Cada forma tem um princípio domi-

1 Rousseau (1985 [1771], p. 11) deu um passo adiante dentro dessa concepção, ao argumentar que cada tipo específico de instituição democrática pode prosperar somente quando é compatível com os costumes de uma sociedade particular. Ainda que sua visão da Polônia fosse inteiramente folclórica, seu argumento era geral: "Se não se conhece a fundo a nação para a qual se trabalha, a obra que faremos para ela, por mais excelente que possa ser em si mesma, pecará sempre pela aplicação e bem mais ainda quando se tratar de uma nação já inteiramente instituída, cujos gostos, costumes, preceitos e vícios estão muito enraizados para poderem ser 
nante: no despotismo é o medo, na monarquia é a honra, na república é a virtude. São esses princípios que fazem funcionar cada forma de governo (“ce qui le fait agir", EL, III, 1)2 . De acordo com Versini (1995, pp. 24-25), a lista de Montesquieu desenvolveu-se gradualmente à medida que ele aprendia sobre a experiência de diferentes nações: no número 645 dos Pensées de 1737-38 os elementos culturais incluíam "a religião", "os costumes e as maneiras"; em De l'esprit des lois esses elementos tornaram-se primeiro "a religião", "os exemplos das coisas passadas", "os costumes", "as maneiras" e, posteriormente, "a religião dos habitantes", "suas inclinações", "seus costumes", "suas maneiras", e "relações entre elas". Temos uma lista sem fim em que tudo parece ser fundamental, das instituições maritais ao celibato dos sacerdotes e à tolerância religiosa.

Além disso, as causas culturais não são as únicas: o clima é essencial, como é a qualidade do solo, o tamanho do território e o "commerce" (a economia). O que, então, causa o que? Versini (1995, p. 38) argumenta que “as causas morais são finalmente 'dominantes' em De l'esprit des lois". Mas ele infere essa conclusão unicamente da ordem final dos tópicos discutidos por Montesquieu, não de quaisquer afirmações explícitas nesse sentido. Por vezes Montesquieu usa apenas a linguagem da compatibilidade, não da causalidade, em passagens como "qual legislador poderia propor o governo popular a semelhantes povos?” (EL, XIX, 2).

Sobretudo, Montesquieu está em busca da "ordem das coisas" ( $E L$, XIX, 1). Ele observa a seguir que "várias coisas governam os homens..." e "à medida que em cada nação uma das causas age com mais força as outras cedem a ela na mesma medida" (EL, XIX, 4). Ao longo de todo o livro, ele enfatiza que as leis educam; não são mero efeito. Concluímos que estão longe de ser óbvias e claras as relações causais entre princípios, por um lado, e culturas, do outro. A mesma conclusão se aplica à relação entre leis e princípios.

O estudo comparativo de formas de governo (pois é disto que se tratava) por Montesquieu prenunciava as dificuldades que as concepções culturalistas tiveram que enfrentar desde então. A primeira consiste em identificar os traços da cultura que têm importância para a forma de governo. A segunda reside em determinar os elos causais entre economia, instituições políticas e cultura.

A hipótese geral de Montesquieu ganhou uma perspectiva "desenvolvimentista" nos escritos dos filósofos morais escoceses, que "transforfacilmente abafados por sementes novas" [NT: Foi utilizada a tradução de Luiz Roberto Salinas Fortes em: Considerações sobre o governo da Polônia e sua reforma projetada. Tradução, apresentação e notas: Luiz Roberto Salinas Fortes. São Paulo, Brasiliense, 1982].

2 EL III, 1 significa De l'esprit des lois, Livro III, capítulo 1. 
maram os estados da sociedade de Montesquieu numa elaborada seqüência de estágios no desenvolvimento histórico da sociedade civil, tendo em vista dar conta do processo para o qual uma nova palavra teve que ser forjada, a saber, civilização" (Collini, Winch and Burrow, 1983: 18). A inovação, portanto, consistiu em pensar as culturas como progredindo da primitiva à civilizada, sustentando que certas formas de vida política somente podem manter-se na segunda. Para os autores desta escola as instituições políticas não poderiam ser simplesmente inventadas $a b$ ovo, introduzidas deliberadamente, mas tinham que corresponder a sentimentos de simpatia, a hábitos de sociabilidade e de deferência e a um cultivado senso de espírito público.

Esse problema- "em que medida governos são matéria de escolha" - deu o título ao primeiro capítulo de Considerations on Representative Government, de John Stuart Mill (1991 [1861]). Para Mill certos padrões culturais são incompatíveis com a democracia: "Um povo rude, ainda que até certo ponto receptivo aos benefícios da sociedade civilizada, pode ser incapaz de praticar as renúncias que ela requer; suas paixões podem ser demasiado violentas, ou seu orgulho pessoal por demais exigente, para evitar o conflito privado e deixar para a lei o desagravo das suas reais ou supostas ofensas" (p. 15). As pessoas podem achar repugnante a forma representativa de governo, podem desejá-la mas serem avessos a ou incapazes de preencher suas condições, ou podem carecer do preparo para exercê-la. No entanto, Mill (pp. 18-19) insistiu em que essas condições são maleáveis: "Esses supostos requisitos das instituições políticas são meros recursos para realizar as três condições ... é exagero elevar esses simples auxílios e recursos a condições necessárias. As pessoas são mais facilmente induzidas a fazer, e fazem com mais facilidade, aquilo a que já estão habituadas; mas as pessoas também aprendem a fazer coisas que são novidade para elas". As pessoas podem não estar preparadas para a democracia, mas podem ser ensinadas a comportar-se como democratas.

A questão espinhosa é a de estabelecer a direção e a cadeia de causalidade. Na medida em que distinguiam tecnologia, riqueza e cultura entendidas como crenças e hábitos, por um lado, de cultura entendida como apreciação de idéias e símbolos, pelo outro, a maior parte das concepções centradas no desenvolvimento, de Adam Smith (Winch,1978, cap. 3) passando pela maioria das teorias de estágios (Comte, Maine, a escola de "política comparada" de Cambridge, Toennies e Durkheim para citar apenas alguns) até a teoria da modernização contemporânea, foram todas ambivalentes acerca da cadeia de causalidade que movia as civilizações de um estágio ao seguinte. Seria o progresso material o gerador das mudanças 
na cultura e nas instituições políticas, ou seriam as transformações culturais que fariam avançar o progresso material e as formas de governo?

A tentativa moderna de resolver essas questões encontra-se no livro de Almond e Verba (1965 [1963]). Este livro foi também responsável pela introdução de uma nova metodologia. Almond e Verba começaram observando que, enquanto aspectos tecnológicos eram facilmente difundidos pelas novas nações, a cultura política ocidental não era tão nitidamente transmissível. Para os autores, existiria uma relação causal entre cultura e democracia: "Para que o modelo democrático do Estado participativo se desenvolva nessas novas nações é preciso mais do que as instituições formais da democracia ... Uma forma democrática de sistema político participativo requer também uma cultura política congruente com ela"(p. 3). Embora Almond e Verba aceitassem, em conformidade com a teoria da modernização, que o desenvolvimento econômico é necessário para a democracia, eles sustentavam que ele não era suficiente, o que se demonstra pela imperfeição das correlações encontradas por Lipset (1959). Em conseqüência, criticavam Lipset por ignorar as bases psicológicas da democratização (p. 9).

Para Almond e Verba a cultura fornece a "base psicológica" da democracia. Além disso, à diferença de Laswell (1946) e outros estudos na linha psicoanalítica, a sua psicologia era mentalista. A cultura é a "orientação psicológica dirigida a objetos sociais" (p. 13). "Quando falamos da cultura política", explicam Almond e Verba, "referimo-nos ao sistema político como internalizado na cognição, nos sentimentos e nas avaliações da sua população". E, finalmente, "a cultura política de uma nação é a distribuição particular de padrões de orientação relativos aos objetos políticos entre os membros da nação".

Conceituada deste modo, a cultura pode ser estudada propondo-se questões a indivíduos, e a cultura não é mais do que a distribuição das respostas. A inovação metodológica consistiu, portanto, em substituir aquilo que se costumava estudar como "o caráter nacional" mediante o exame da história nacional, ou como "personalidade modal" pelo exame dos padrões de socialização infantil manifestos nas respostas às perguntas sobre o que as pessoas conheciam, apreciavam e valorizavam. Mesmo tendo sido amplamente criticado por razões conceituais e metodológicas (Barry, 1978; Wiatr, 1979), o estudo de Almond e Verba deu origem a uma nova indústria.

Atualmente, perguntar às pessoas sobre o seu conhecimento de instituições políticas, sobre suas preferências quanto a sistemas de governo e sobre suas avaliações de processos políticos, agentes e resultados é uma 
atividade rotineira. Respostas a essas questões são interpretadas como signos de estabilidade democrática e, com freqüência, são lidas com ansiedade: o Brasil, por exemplo, parecia estar no limite em 1991, pois somente 39\% dos perguntados consideravam a democracia como sempre sendo o melhor sistema de governo, em contraste, digamos, com o Chile, onde, em 1990, $76 \%$ o faziam. A questão que permanece aberta é a de se saber se tais respostas predizem de fato se a democracia sobreviverá ou não.

A cultura que Almond e Verba identificaram como democrática, a "cultura cívica", ostentava uma "misteriosa" semelhança com o que se poderia esperar encontrar nos Estados Unidos. Não surpreende que os Estados Unidos se ajustassem melhor ao ideal da cultura democrática, seguidos pelo Reino Unido. E, sendo a democracia nesses países mais antiga - mais estável - do que na Alemanha, na Itália ou no México, a hipótese central do estudo encontrou apoio nos dados testados: um tipo particular de cultura política é requisito para uma democracia estável.

Inglehart (1990) e Granato, Inglehart e Leblang (1996) procuraram validar esse enfoque. A "cultura cívica" de Inglehart (1990) consiste em três indicadores: (1) confiança interpessoal, (2) satisfação vital e (3) apoio à mudança revolucionária (que se espera ser nociva à democracia). Ele $\mathrm{e}$ seus colaboradores descobriram que essas variáveis, quando tomadas em conjunto, relacionam-se estatisticamente com o número de anos contínuos de democracia entre 1900 e 1980 e entre 1920 e 1995, numa amostra de 24 países. No entanto persistem dúvidas (Jackman e Miller, 1996): é esta uma medida apropriada de estabilidade democrática? Pode-se extrair tais inferências com base numa amostra com pesado viés em favor de democracias duradouras? Qual é a direção da causalidade?

Muller e Seligson (1994) reanalisaram os dados de Inglehart, adicionando alguns países latino-americanos, para identificar a direção da causalidade. Concluíram que, no melhor dos casos, é a estabilidade democrática que gera a cultura democrática e não vice-versa. Eles também observaram, como Jackman e Miller haviam feito, que os indicadores de "cultura cívica" de Inglehart não andam juntos: a confiança é independente da preferência por mudança gradual, enquanto que satisfação vital pouco tem a ver com "cultura democrática". Eles descobriram que a confiança interpessoal é um efeito da estabilidade democrática e não afeta por seu turno a democracia, enquanto a inclinação em favor da mudança gradual não está relacionada com a experiência de longo prazo da democracia, e tem um efeito positivo na democracia. Mesmo essa descoberta, contudo, permanece sensível à composição da amostra de países. 
Com efeito, uma limitação do enfoque de survey é que ele se revela mais apropriado à questão da estabilidade democrática do que à questão sobre se a democracia é mais provável de estabelecer-se em sociedades dotadas de certos traços culturais particulares. As ditaduras raramente permitem que pesquisadores de survey façam questões sobre democracia - tipicamente o fazem apenas na sua agonia mortal. Por isso os dados de survey sobre atitudes políticas sob ditaduras são escassos, tornando difícil determinar se os democratas geram democracias ou se democracias geram democratas. Maravall (1995) constatou que a apoio à democracia cresceu na Espanha entre 1966 e 1976 e no Chile durante os últimos anos de Pinochet, enquanto o apoio aos militares declinou no Brasil entre 1972 e 1990, concluindo que "em todos esses casos as democracias foram precedidas por um aumento no número de democratas"(p. 17). No entanto, Schmitter e Karl (1991) sustentaram que é a democracia que gera democratas, não vice-versa.

\section{O que importa na cultura, e como?}

Como indica esse breve esboço histórico, a concepção de que a democracia requer uma base cultural específica passou por várias reencarnações. Parece haver algo na cultura que é necessário para a democracia emergir e durar. Mas, o que precisamente? Para Montesquieu, era uma força motivadora irracional ("as paixões humanas que a fazem mover-se", $E L$, III, 1) - temor, honra, virtude - que, por sua vez, refletem religiões, costumes e maneiras. Os teóricos dos estágios procuravam por sentimentos, hábitos, assim como por um senso racional de bem público. Mill foi mais sistemático, ao distinguir entre uma preferência pela democracia, as diferenças de temperamento necessárias para sustentá-la e um senso de comunidade. Almond e Verba buscavam crenças, afetos e avaliações dos processos e dos resultados políticos. Inglehart queria saber se as pessoas estão satisfeitas com suas vidas, se confiam uns nos outros, e se gostam de mudanças revolucionárias. Outros pesquisadores de survey perguntaram se as pessoas dão valor à democracia por si mesma, sem considerar as condições enfrentadas e os resultados gerados.

Essa ambigüidade, e a confusão que ela engendra, é especialmente visível na tentativa de Weingast (1997) de reconciliar explicações aparentemente rivais da estabilidade democrática. Weingast propôs-se demonstrar que, para a democracia ser estável, os cidadãos devem adotar uma visão compartilhada do que constitua atos ilegítimos do Estado e devem estar prontos a agir contra as transgressões desses limites quando venham a ocor- 
rer. A primeira tarefa requer uma coordenação de crenças, e a segunda, uma coordenação de ações. O primeiro problema é resolvido quando os cidadãos se pautam pelos limites prescritos pela Constituição e/ou especificados por pactos políticos explícitos. O segundo é resolvido quando, temendo interferências estatais futuras, os cidadãos unem-se numa frente contra atos ilegítimos do Estado, mesmo quando tiram benefícios correntes deles. Em suma, a democracia é estável quando indivíduos estão preparados para rebelar-se em uníssono sempre que o Estado transgrida certos limites.

Qual é, então, o papel da cultura no apoio a esse equilíbrio democrático? Weingast (p. 253) tem o cuidado de enfatizar que o seu relato não é de índole causal, em que valores tornariam estável a democracia, nem o reverso. Uma cultura particular e a estabilidade democrática são apenas aspectos diferentes de situações em que uma sociedade resolve seus dilemas de coordenação. Mas quais são exatamente os aspectos da cultura que servem de apoio a essas situações? No primeiro nível, destacam-se duas: um consenso sobre os limites das ações estatais legítimas e um sentido comum do "dever" de defendê-lo ${ }^{3}$. Mas, para agradar a todos, Weingast também os caracteriza como "consenso sobre valores e sobrea a estabilidade da democracia" (p. 246), "consenso sobre as regras" (p. 257), "estima" por limites às ações do Estado (p. 251), "confiança" (p. 257) e "tolerância mútua" (p. 257). Isto é uma operação puramente verbal e somente obscurece a questão.

Para que as concepções culturalistas forneçam uma explicação convincente das origens e da vida da democracia, cabe-lhes especificar o que e como a cultura importa. Comecemos por distinguir os diferentes aspectos da cultura que podem importar ${ }^{4}$.

\footnotetext{
3 Weingast pressupõe implicitamente que o Estado é uma ameaça potencial para todos: a possibilidade de uma aliança estável entre o Estado e determinadas classes é eliminada. Em consequiência, interpreta mal suas próprias conclusões quando diz que agem por um senso de "dever" quando se opõem ao Estado. Que tipo de "dever" é este, movido unicamente pelo interesse próprio?

4 Uma nova moda entre especialistas em teoria dos jogos consiste em interpretar cultura como crenças acerca de comportamentos que ocorreriam "fora de equilíbrio" ('out of equilibrium' beliefs'), isto é, crenças sobre o que sucederia se algo que nunca vem a ocorrer se realizasse. Suponhamos que a burguesia esteja considerando se deve atender às demandas dos trabalhadores ou recorrer aos militares para reprimi-las. A burguesia acredita que os militares não iriam reprimir, e, em conseqüência, atende às demandas dos trabalhadores. Logo, a crença em que os militares são interferem na política, uma crença sobre algo que se daria fora de equilíbrio, sustenta a estabilidade democrática. Ou suponhamos que os trabalhadores acreditam que os militares os reprimiriam se instados a fazê-lo pela burguesia: então a burguesia, sabendo que os trabalhadores moderariam suas exigências por medo da intervenção militar, não recorreria aos militares. Neste caso é a crença dos trabalhadores num estado fora de equilíbrio, de que os militares são propensos à intervenção, que sustenta a democracia. O problema com explicações desse tipo é que, enquanto crenças sobre estados de equilíbrio podem ser baseadas em observações de eventos passados e podem ser revisadas racionalmente, as crenças sobre estados fora de equilíbrio são completamente arbitrárias. Logo, "cultura" torna-se um mero nome para a caixa preta acerca das crenças. Essa não parece ser uma linha de investigação fecunda.
} 
Primeiro, as pessoas valorizam a democracia em si mesma, independentemente dos resultados que ela possa gerar. Querem criar e defender a democracia contra ameaças porque este regime funda-se na igualdade política (Tocqueville), porque é uma expressão da liberdade (Dunn, 1992), ou por qualquer outra razão não instrumental. Elas acreditam que a democracia é incondicionalmente o melhor (ou o menos mau) sistema de governo, dizem-no quando perguntados, ou agem como se assim acreditassem.

Segundo, as pessoas consideram que devem obedecer as decisões resultantes de regras que têm o seu "assentimento"5. Colocamos aspas em "assentimento" porque o acordo em questão pode ser putativo: as pessoas teriam escolhido essas regras se tivessem sido consultadas. A democracia é então legítima no sentido de que as pessoas estão dispostas a aceitar decisões cujo conteúdo será ainda determinado, desde que essas decisões resultem da aplicação das regras. Mesmo quando não os apreciam, as pessoas obedecem aos resultados do jogo democrático, porque eles resultam da aplicação das regras que aceitam. Neubauer (1967, p. 225) sustentou que a "socialização nas "regras do jogo" é um requisito para a democracia. A teoria da obrigação política tem uma segunda variante, que enfatiza a participação no lugar das regras. Nessa versão, as pessoas consideram seu dever obedecer resultados em cuja produção tiveram oportunidade de participar. Em igualdade com todos os demais, tiveram como tornar públicas suas razões (Cohen, 1997), ou pelo menos votar, e ter tido essa oportunidade torna os resultados normativamente obrigatórios. A "cultura participativa" é, assim, a chave para a estabilidade democrática.

Terceiro, as pessoas têm valores e talvez características de temperamento ("personalidade democrática", na linguagem dos anos 50) que oferecem apoio à democracia. Lipset $(1959$, p. 153) sustentou que "se um sistema político não for caracterizado por um sistema de valores que permita o ‘jogo' pacífico do poder, não pode haver democracia estável”. Essas características podem incluir "virtude republicana", confiança ${ }^{6}$, empatia, tolerância, moderação ou paciência. As pessoas podem amar a coletividade mais do que a si mesmas; podem confiar em que o governo não vai tirar uma vantagem desleal mesmo quando está nas mãos dos seus adversários; podem estar prontos a respeitar a validade de concepções e interesses

5 Sobre as dificuldades dessa concepção como uma teoria positiva da ação, ver Dunn (1996, cap. 4)

6 Confiança é o mais novo termo da moda entre teóricos da democracia. No entanto é de se perguntar se cidadãos democráticos deveriam confiar tanto em seus governos. Não deveriam, em vez disso, monitorar o que os governos fazem e puni-los apropriadamente? 
diferentes dos seus; podem estar dispostos a aceitar que outros também devam ter direitos; ou podem estar dispostos a esperar pela sua vez.

Quarto, o que pode importar para tornar possível a democracia não é tanto o que as pessoas compartilham quanto o que fazem: "consenso"7. John Stuart Mill (1991, p. 230) foi talvez o primeiro a contribuir para a longa sequiência de argumentos na linha de "instituições livres são praticamente impossíveis num país composto por nacionalidades diferentes. Entre um povo desprovido de senso de comunidade, ainda mais quando se lêem e se falam línguas diferentes, a opinião pública unida necessária para o funcionamento do governo representativo não pode existir". Se não compartilham características básicas como a língua, a religião ou a etnicidade, as pessoas não têm o suficiente em comum para sustentar a democracia. Mas a homogeneidade no tocante a tais características básicas não é suficiente: o "acordo" sobre certos valores básicos, sobre as regras do jogo, ou sobre o que quer que seja, é requisito para o funcionamento da democracia (Dahl, 1956; Lipset, 1959; Eckstein, 1961) ${ }^{8}$. Assim, Weingast (1997, p. 254) pensa que a democracia é instável na América Latina porque "os estados latino-americanos não são caracterizados por um conjunto comum de valores dos cidadãos a respeito do papel apropriado ao governo".

$\mathrm{O}$ argumento centrado no consenso por vezes aponta para tradições nacionais de decision-making. Assim, o conselho de aldeia escandinavo medieval (thing) é citado como indicando que os escandinavos estavam prontos para aceitar parlamentos democráticos (Esposito e Voll, 1996, p. 22). Entretanto, esse argumento tem dois gumes: a evocação da mesma tradição de decision-making na Indonésia ou na África é usada para argumentar que a cultura é hostil à democracia, pois esta envolve conflito mais do que consenso.

É claro que esses suportes culturais da democracia não precisam ser mutuamente exclusivos. Mesmo se alguns podem ser mais importantes para gerar a democracia e outros em fazê-la durar, qualquer um ou todos eles pode ser necessário para as pessoas lutarem pela democracia quando vivem numa ditadura e para dar-lhe apoio uma vez estabelecida. Mas, caso se espere que as concepções culturalistas tenham valor explicativo, então

7 Esse pode ser um consenso "por sobreposição" (overlapping: Rawls, 1993) uma vez que as razões que levam as pessoas a aceitarem um determinado arranjo institucional podem variar entre grupos que sustentam valores "fundamentais" diferentes.

8 Eckstein (1961), assim como Eckstein e Gurr (1975), estão entre os que argumentam que a política democrática também exige que o valor democrático penetre em grupos sociais menos abrangentes, como as famílias, as comunidades e os locais de trabalho. Para uma posição contrária veja-se Linz (1996). 
elas precisam distinguir e especificar. De outro modo nunca será possível concluir que a cultura não importa.

A segunda questão diz respeito à causalidade. Pois, mesmo se todas as democracias duradouras revelassem compartilhar uma "cultura democrática" determinada, essa observação não seria suficiente para determinar o que antecede o que: a cultura democrática ou as instituições democráticas. Com risco de ser pedante, distinguimos a seguir as diferentes cadeias causais que podem conectar desenvolvimento econômico, transformações culturais e instituições políticas.

Primeiro, a cultura causaria tanto o desenvolvimento econômico quanto a democracia, qualquer seja a conexão causal entre os dois últimos elementos. Esta é a concepção que designamos como "fortemente culturalista". O protestantismo é um candidato a uma cultura que promove tanto o desenvolvimento quanto a democracia (ver abaixo); pelo menos, esta era a visão de Lipset em 1994. Por seu lado, o catolicismo, no entender de Wiarda (1981) impede tanto o desenvolvimento quanto a democracia na América Latina ${ }^{9}$. Por muito tempo, o confucionismo foi visto como um obstáculo a ambos, mas, agora, parece haver uma tendência a vê-lo como bom para o desenvolvimento. Ainda assim, alguns ainda insistem, notavelmente o ex presidente Lee Kuan Yew de Singapura, em tomar o confucionismo como oposto à democracia.

Segundo, tanto o desenvolvimento quanto a cultura seriam, de modo independente, necessários para tornar possível a democracia. E, mesmo que o desenvolvimento gere certas transformações culturais, estas são insuficientes para gerar a cultura democrática, a qual, por sua vez, é necessária para que a democracia surja e sobreviva. Essa era a concepção, ainda fortemente culturalista, de Almond e Verba discutida acima.

Terceiro, uma cultura particular seria necessária para tornar possível a democracia, mas essa cultura seria automaticamente gerada pelo desenvolvimento econômico. Lipset (1959, 1960) descreveu várias maneiras pelas quais o desenvolvimento gera precondições culturais para a democracia: ao promover a moderação e a tolerância, e ao propiciar às

${ }^{9}$ De acordo com Wiarda (1981) os sistemas políticos da América Latina contemporânea são produtos de uma cultura política que é específica da região e incompatível com a democracia. Essa cultura, que ele denomina "modelo corporativo", resulta diretamente do "sistema colonial espanhol de organicismo, patrimonialismo, senhorio, corporativismo e feudalismo"(p. 39). Quando aplicado a países particulares, esse enfoque conduz a observações como a de que "a cultura política dominicana não tem sido historicamente favorável ao governo democrático. Consideramos isso um fator muito importante. A cultura política dominicana, herdada da Espanha, tem sido absolutista, elitista, hierárquica, corporativa e autoritária” (Wiarda, 1989, p. 450). 
camadas mais baixas a adoção de "perspectivas temporais mais longas e visões da política mais complexas e gradualistas" (1959, p. 83). Fica claro que nessa concepção as culturas, no plural, são maleáveis o suficiente para se tornarem "modernizadas" junto com outros aspectos das sociedades como um efeito do desenvolvimento econômico. Desse modo, a cadeia causal vai do desenvolvimento, através da cultura, à democracia. Esta é uma concepção "fracamente culturalista".

Quarto, uma cultura particular seria necessária para a persistência da democracia, mas essa cultura emergeria por efeito de instituições democráticas tão logo estas estivessem instaladas. Essa era a visão de John Stuart Mill, para quem, como vimos acima, embora as pessoas prefiram fazer o que sabem fazer, elas podem ser ensinadas a fazer coisas novas. O impacto educacional das leis foi o tema persistente de Montesquieu, assim como de Tocqueville. Segundo essa visão, todas as democracias duradouras deveriam ter a mesma cultura política, uma cultura que resultaria das instituições democráticas e que, uma vez constituída, daria suporte às instituições.

Quinto, na visão não culturalista, a democracia emergeria e se manteria de modo independente da cultura. A democracia pode ou não gerar homogeneidade cultural, mas a cultura não teria qualquer impacto causal sobre a durabilidade de instituições democráticas.

Dada a escassez de dados sobre cultura, as primeiras três explicações não podem ser testadas sistematicamente para um grande número de países. No entanto, as explicações não culturalistas podem ser submetidas a teste.

\section{Uma explicação não culturalista}

A concepção não culturalista tem forte apoio empírico. Nessa visão a democracia sobrevive porque é mais vantajoso para as forças políticas relevantes, pautando suas ações por puro interesse próprio, obedecer o veredicto das urnas do que fazer qualquer outra coisa. Os perdedores numa competição democrática podem ter incentivos no curto prazo para rebelarse, não aceitando os resultados do turno atual. No entanto, se existir uma possibilidade de ganhar as eleições futuras e os benefícios esperados destas vitórias forem grandes o suficiente, perdedores preferirão aceitar os veredictos das urnas. O mesmo argumento explica porque os ganhadores aceitam submeter-se ao teste das urnas no futuro. Nestes termos, a democracia é um equilíbrio porque as diferentes forças políticas consideram que 
obedecer aos seus veredictos atende melhor aos seus interesses (Przeworski, 1991, cap. 1) ${ }^{10}$.

Para contar um relato estilizado (Przeworski, 1996), tomemos um ator político, coletivo pela definição de "político", que se pergunta se deve participar do jogo político - com alguma possibilidade de ganhar eleições e de ter acesso a uma parcela de despojos discricionários caso vença - ou se deve lutar pela ditadura, com certo custo para os recursos produtivos e com alguma chance de tornar-se o ditador. A escolha, neste caso, é entre conseguir certa parcela da renda caso se permaneça sob a democracia ou correr o risco de lutar pela ditadura na esperança de conseguir toda a renda discricionária, ainda que ao custo de destruição temporária de alguma riqueza. Trata-se, pois, de uma escolha entre "uma parte do mais" e "o todo do menos" (ambas sendo loterias).

Introduzindo pressupostos econômicos tradicionais, suponhamos que os benefícios do aumento de consumo declinem à medida que os atores políticos se tornam mais ricos. Nessas condições, o ganho de vencer-se a luta pela ditadura é menor numa sociedade mais rica. Por outro lado, se a função de produção tem retornos decrescentes em relação aos recursos produtivos, o catch-up da destruição de uma parte delas durante a guerra pela ditadura é mais rápido em níveis mais baixos de riqueza. Segue-se que em países pobres o valor de tornar-se um ditador e o custo acumulado da destruição de estoques de capital é mais baixo. Em nações ricas, o ganho de conseguir-se tudo ao invés de uma parte da renda total é mais baixo e a recuperação da destruição é mais lento. Como resultado, a luta pela ditadura, a "rebelião", é mais atraente em nações mais pobres. É, talvez, ainda mais óbvio que a rebelião seja uma alternativa mais atraente para aquelas forças políticas que esperam receber uma parcela menor da renda sob a democracia11.

Esse modelo simples conduz a várias predições empíricas: (a) a probabilidade de que uma democracia persista deverá aumentar com a riqueza (renda) presente e futura; (b) a probabilidade de que uma democracia se mantenha deverá ser mais alta quando nenhuma força política

\footnotetext{
10 Cabe uma advertência ao leitor versado em teoria dos jogos. Na maioria das situações há diversos equilíbrios. Um é "guerra": o ganhador espera que o perdedor se rebele, o perdedor espera que o ganhador não fará eleições, e eles partem para o confronto. Outro é ditadura sem guerra: o ditador não chega a provocar a oposição, e esta acha melhor aceitar a ditadura do que lutar. Desse modo, um equilíbrio democrático, quando existe, não é mais do que um entre vários, o que significa que Weingast (1997) está certo ao enfatizar a importância da coordenação. Ainda assim, se a escolha do equilíbrio depende do desenvolvimento econômico, então a cultura não tem papel a desempenhar nela.

11 Note-se que as taxas de preferência temporal são fixas e exógenas nesse modelo. As conclusões não dependem do pressuposto de que a riqueza torne as pessoas mais pacientes.
} 
domine completamente o sistema político; (c) em países muito pobres, a democracia será subvertida por ocupantes de cargos de governo tanto quanto pelos não ocupantes; em países com nível médio de riqueza a democracia será subvertida com mais frequiência por outsiders (por "perdedores") do que por ocupantes de cargos; e em países ricos a democracia terá o apoio tanto dos vencedores quanto dos ganhadores.

Quando examinamos alguns padrões empíricos relativos a quase todas as democracias que existiram em qualquer lapso de tempo entre 1950 e $1990^{12}$, o fato que mais chama a atenção é que democracia alguma jamais foi subvertida neste período num país com uma renda per capita superior à da Argentina em 1976.

A probabilidade de sobrevivência da democracia aumenta monotonicamente com a renda per capita. Em países com renda per capita inferior a 1.000 dólares a probabilidade de que a democracia morreria durante um certo ano era de 0,1216 , o que implica uma expectativa de vida levemente superior a 8 anos. Entre 1.001 e 2.000 dólares, essa probabilidade era de 0,0556 , para uma duração esperada de em torno de 18 anos. Acima de 6.000 dólares, as democracias podiam esperar durar para sempre ${ }^{13}$.

Além disso, as democracias, em especial as pobres, são altamente vulneráveis a crises econômicas. A vida esperada de uma democracia muito pobre que experimenta um ano de declínio econômico é de apenas 5,6 anos. No entanto, democracias muito pobres - aquelas abaixo de 1.000 dólares de renda per capita - quando sua renda cresce têm chances de sobreviver da mesma ordem que as democracias mais ricas - aquelas entre 1.000 e 3.000 dólares - quando a renda destas declina.

Vários outros fatores afetam a sobrevivência das democracias, mas todos eles perdem sua força quando comparados à renda per capita. Dois deles são particularmente relevantes para a perspectiva da escolha racional. Em primeiro lugar, as democracias têm mais chance de sobreviver quando nenhum partido controla uma grande parcela (mais do que dois terços para ser preciso) das cadeiras legislativas. Em segundo lugar, as democracias são mais estáveis quando os chefes de governo mudam com freqüência,

12 Todos os resultados estatísticos apresentados aqui baseiam-se em Przeworski, Alvarez, Cheibub e Lijmongi 2000. Os dados cobrem 135 países e um total de 4.126 anos. Entre eles estavam 100 democracias, que em conjunto duraram 1.645 anos. Todos os dados sobre renda estão expressos dólares norte-americanos de 1985 , convertidos pelo método da paridade da capacidade de compra.

13 Esses padrões são investigados de maneira mais profunda e usando as técnicas estatísticas padrões em Przeworski, Alvarez, Cheibub e Limongi 2000. O leitor interessado nos detalhes da análise empírica apresentada no artigo deve consultar o livro citado acima. 
mais do que uma vez em cinco anos porém menos do que uma vez em dois anos. Essas observações - e ambas sobrevivem estatisticamente em análises multivariadas - levam a uma importante conclusão: a probabilidade da sobrevivência da democracia cresce quando nenhuma força política domina de modo completo e permanente. As democracias são menos estáveis quando um partido tem controle irrestrito sobre a legislatura ou quando os chefes do Executivo permanecem no cargo por longo tempo.

Os casos em que democracias foram subvertidas seguem o padrão previsto pelo modelo: democracias pobres (com renda per capita abaixo de 1.000 dólares) são derrubadas tanto pelos ocupantes do poder como pelos grupos fora do poder, democracias em países com renda entre $1.000 \mathrm{e}$ 6.000 estão muito mais sujeitas a serem derrubadas por outsiders, e democracias ricas não são derrubadas por ninguém.

É claro que sempre restam interpretações alternativas. Uma delas seria a de que renda não passa de substituto para educação e que pessoas mais educadas tenderão a incorporar valores democráticos. No entanto, ao passo que os anos acumulados de educação de um membro médio da força de trabalho, que é a medida de estoque educacional que possuímos, afeta a probabilidade de sobrevivência da democracia de modo independente da renda, o efeito da renda mantém-se quando controlamos para educação e é duas vezes mais significativo estatisticamente.

Não encontramos evidência de habituação à democracia. As chances de sobrevivência da democracia não são afetadas pelo fato de termos observado que aquele mesmo país vivia sob uma democracia no ano anterior. Para que fosse verdade que democracias se "consolidam", a probabilidade condicional de que um regime irá morrer durante um certo ano, considerando-se que sobreviveu até então (a "taxa de risco"), deveria declinar com sua idade. Se for assim, democracias têm mais possibilidade de sobreviver quanto mais "velhas" forem. Isso é verdade quando a idade do regime é considerada sozinha. Mas, tão logo se controla por renda per capita, as taxas de risco tornam-se independentes da idade, o que significa que, para um dado nível de desenvolvimento, democracias têm aproximadamente a mesma chance de morrer qualquer seja sua idade. Como as chances de sobrevivência da democracia em países mais ricos são maiores, as taxas de risco não corrigidas por renda declinam porque os países se desenvolvem, não porque a passagem do tempo leve à consolidação da democracia. Portanto, mesmo que habituação à democracia gere uma cultura democrática, é a riqueza, e não a cultura, que mantém as democracias vivas.

Fatores econômicos não têm um efeito igualmente forte para a sobrevivência de ditaduras. A probabilidade de que uma ditadura ceda seu 
lugar uma democracia aumenta à medida que os países se tornam mais ricos, para então declinar de novo tão logo se tornam ricos o bastante. Crises econômicas têm um efeito mais fraco na sobrevivência de ditaduras. Com efeito, análises estatísticas indicam que é quase impossível prever transições à democracia, mesmo com toda a gama de fatores observáveis, sejam eles econômicos ou culturais. Parece que as ditaduras simplesmente correm muitos riscos e são vulneráveis a uma ampla variedade de razões.

Entretanto, mesmo se fatores econômicos desempenham um papel mais importante em fazer as democracias sobreviver do que emergir, a renda per capita e seu crescimento são suficientes para explicar a dinâmica de ambos os regimes. Para testar a força preditiva desses fatores recorremos a uma simulação. Tomamos os 135 países incluídos em nossa análise tomando como parâmetros o regime e a renda per capita quando primeiro foram observados (1950, ou o ano de independência, ou o primeiro ano em que se tornaram disponíveis dados econômicos) e as taxas de crescimento econômico observadas durante todo o período até 1990 (ou o último ano para o qual estão disponíveis dados econômicos). Estes países hipotéticos mudarão de regime de acordo com as probabilidades empiricamente observadas para o conjunto de casos no mesmo nível de renda e com aquela taxa de crescimento. Como as probabilidades de sobrevivência dos regimes são, portanto, as mesmas para qualquer país que experimente uma dada taxa de crescimento relacionada a um dado nível de renda, o pressuposto é de que a cultura não afete o surgimento e a sobrevivência da democracia. Com base nisso geramos 1.000 "histórias" para cada país, e comparamos os padrões baseados nesses pressupostos com aqueles efetivamente observados. Os padrões simulados reproduzem as histórias reais de maneira quase perfeita: a correlação entre as proporções de tempo preditas e observadas que cada país permanece sob cada regime é de 0,91 .

Conclui-se que as evidências em favor dos fatores econômicos são esmagadoras. Não é necessário recorrer à cultura para reproduzir os padrões de alternância entre os regimes efetivamente observados. É verdade que ainda seria possível defender a posição culturalista mediante o argumento de que alguma cultura, digamos a "cultura do mercado", é o que causa o desenvolvimento em primeiro lugar, e que a explicação final ainda é, portanto, cultural. Isso até pode ser o caso, mas essa linha de investigação conduz a uma regressão ao infinito, pois, sempre se pode perguntar o que causa o surgimento da "cultura do mercado", e assim por diante. Portanto, nós paramos por aqui. 


\section{CULTURAS, A CULTURA DEMOCRÁTICA E A DEMOCRACIA}

Pode-se dizer que determinadas culturas, identificáveis quanto ao resto, sejam favoráveis ou desfavoráveis à emergência e durabilidade das instituições democráticas? A questão é a seguinte: suponhamos que observássemos que, independente da sua riqueza e outros fatores, todos os países com uma alta proporção de protestantes sejam democracias, e nenhum país com uma baixa proporção de protestantes o seja. Teríamos então prova prima facie de que, seja o que for a "cultura democrática", o protestantismo fornece seus ingredientes necessários. Note-se, porém, que, se não conseguirmos achar tais padrões, isso pode dever-se a duas razões diferentes: seja porque 0 surgimento e a durabilidade da democracia dispensa o recurso a um conjunto determinado de padrões culturais ou porque, embora a democracia tenha requisitos culturais e barreiras culturais, todas as culturas são, ou pelo menos podem ser tornadas, compatíveis com esses padrões.

Primeiro examinaremos a questão da compatibilidade de culturas particulares, no plural, com a cultura democrática. Em seguida examinaremos alguns padrões empíricos.

\section{Culturas e a cultura democrática}

Historicamente a discussão desse tópico deu-se principalmente em torno de culturas identificadas por religiões dominantes. A idéia da força causal primária da religião é devida ao argumento de Max Weber (1958 [1904-05]) de que a "vocação" ascética religiosamente motivada para a acumulação foi a chave do sucesso econômico do capitalismo. Weber (p. 180) sustentava que "um dos elementos fundamentais do espírito do capitalismo moderno, e não só dele mas de toda a cultura racional moderna - a conduta racional com base na idéia de vocação - nasceu ... do espírito do ascetismo cristão". Esse "espírito do capitalismo, no sentido de um específico padrão de vida que reivindica sanção ética para si ..." (p. 58) foi a principal explicação para a diferença entre protestantes (ou pelo menos os ascéticos entre eles) e outras religiões no tocante à conduta econômica (p. 40).

Weber quase nada tinha a dizer sobre as consequiências desse espírito do capitalismo para a política em geral, e em particular sobre a democracia (sobre a qual tinha crenças ambivalentes e mutáveis). Há uma passagem (p. 45) no seu estudo sobre a ética protestante e o espírito do capitalismo na qual ele cita Montesquieu quando este afirma que os ingleses "progrediram mais do que qualquer povo no mundo em três coisas impor- 
tantes: na piedade, no comércio e na liberdade", para em seguida perguntar, talvez em termos retóricos: "Não será possível que essa superioridade comercial e a adaptação deles às instituições políticas livres seja ligado de algum modo àquela piedade que Montesquieu lhes atribui?". Entretanto ele não deu seqüência a essa idéia e, no final do texto (p. 182) simplesmente anunciou que "a próxima tarefa seria mais a de mostrar o significado do racionalismo ascético ... para o conteúdo da ética social prática, em termos de tipos de organização e funções de grupos sociais desde o convento até o Estado". Mas neste ponto ele parou.

Ainda assim, a idéia de que Weber teria visto no protestantismo a fonte da democracia moderna é difundida entre os cientistas sociais contemporâneos. No artigo mais influente sobre as condições da estabilidade democrática, Lipset (1959, p. 165) sustentou que "argumentou-se, por Max Weber entre outros, que os fatores responsáveis pela democracia nessa área [o Noroeste europeu e seus derivados de língua inglesa na América e Australasia] constituem uma concatenação de elementos historicamente única, parte do complexo que também produziu o capitalismo nessa área", visto que "a ênfase no protestantismo na responsabilidade individual promoveu a emergência de valores democráticos"14. Por sua vez, o catolicismo, na visão de Lipset (pp. 72-73), opunha-se à democracia na Europa anterior à Segunda Guerra Mundial e na América Latina.

No seu discurso presidencial na American Sociological Association, Lipset (1994, p. 5) atribuiu as origens dessas concepções não a Weber mas a Tocqueville, de novo sem indicar qualquer texto específico. No entanto, Tocqueville (1961, vol. I, p. 427), referindo-se aos imigrantes irlandeses, não apenas observou que "esses católicos ... formam a classe mais republicana e a mais democrática que exista nos Estados Unidos", para contudo acrescentar em seguida que "é um erro considerar a religião católica como um inimigo natural da democracia", assinalando em particular os traços igualitários do catolicismo.

O catolicismo não é o pior inimigo da democracia: a taça fica com o islamismo e o confucionismo (Eisenstadt, 1968, pp. 25-27). Huntington (1993, p. 15) constatou: "Não há desacordo entre os estudiosos no tocante à proposição de que o confucionismo tradicional foi ou não democrático ou

14 Lipset não identifica qualquer texto específico de Weber. Tampouco o fazem Almond e Verba (1965 [1963], p. 8), ao afirmarem que "o desenvolvimento do protestantismo, e especialmente das seitas não conformistas, foram considerados vitais para o desenvolvimento de instituições estáveis na Grã Bretanha, no antigo Commonwealth e nos Estados Unidos" (itálicos adicionados). 
antidemocrático". Visões similares acerca do islamismo são abundantes (Gellner, 1991, p. 506; Lewis, 1993, pp. 96-98).

Lee Teng Hui (1997), então presidente de Taiwan, discorda. Lee encontrou no confucionismo tradicional uma ênfase no governo limitado que é essencial à democracia. Numa revisão sistemática de escritos sobre confucionismo e democracia, Im (1997), como outros antes dele, encontra um quadro muito mesclado: por um lado, o confucionismo não tem um conceito de sociedade civil, nem um conceito de direitos individuais (no lugar disso tem um conceito de papéis que as pessoas deveriam desempenhar), ou do rule of law, mas, em contrapartida, tem fundas tradições de governo limitado, reconhece o direito à rebelião contra dirigentes que se desviam do "caminho" prescrito, é tolerante quanto à religião e se opõe ao militarismo. Além disso, na Coréia pelo menos, uma pluralidade de opiniões, uma esfera pública, existiu durante os seis séculos da dinastia Xosun.

A discussão no interior do islamismo e sobre ele é ainda mais complexa. De acordo com Esposito e Voll (1996) os três fundamentos do islamismo prestam-se, e foram sujeitos a, interpretações mais ou menos antidemocráticas. Assim, o princípio da unidade de Deus (tahwid), embora exija consistência relativamente às leis divinas, pode deixar a interpretações delas a qualquer muçulmano capaz e qualificado, e não precisa ser inconsistente com um sistema de governo no qual o executivo "é constituído pela vontade dos muçulmanos, que também têm o direito de depô-lo (p. 24), ou com "uma assembléia cujos membros são os reais representantes do povo" (p. 27). De modo similar o princípio do representante de Deus na Terra (khilafah) não precisa ser interpretado em termos monárquicos, podendo ser estendido a todos os homens e mulheres. Finalmente, as tradições de consulta, consenso e julgamento interpretativo independente podem ser usadas como argumentos a favor ou contra a democracia. Com efeito, Eickelman e Piscatori (1996) mostram que essas interpretações doutrinárias serviram no passado e servem agora para justificar arranjos políticos inteiramente diferentes.

Há várias razões para duvidar que culturas, ou civilizações, como Mazrui (1997, p. 118) prefere pensar sobre o islamismo, forneçam requisitos para a democracia, ou constituam barreiras irremovíveis a ela. Primeiro, os argumentos que relacionam a civilização à democracia parecem terrivelmente ex-post: se muitos países dominados por protestantes são democráticos, procuramos traços no protestantismo que promovem a democracia; se nenhum país muçulmano é democrático, obviamente deve haver algo de antidemocrático no islamismo. Eisenstadt (1968), por exem- 
plo, acha que a civilização indiana tem o que a democracia pede, ao contrário do confucionismo e do islamismo... Seria interessante ver o que ele acharia se a China fosse democrática e a Índia não ${ }^{15}$.

Segundo, pode-se achar elementos em toda cultura, o protestantismo incluído, que parecem compatíveis e outros que parecem incompatíveis com a democracia. A legitimação protestante da desigualdade econômica, para não falar da própria ética do interesse próprio, oferece uma base moral pobre para a convivência e a solução de conflitos de maneira pacífica. Outras culturas são autoritárias mas igualitárias, hierárquicas mas respeitosas do direito de rebelião, comunais mas tolerantes da diversidade, e assim por diante. É escolher e pegar ${ }^{16}$.

Terceiro, cada uma das tradições religiosas foi historicamente compatível com uma ampla gama de arranjos políticos. Essa gama não é a mesma para tradições religiosas diferentes, mas ampla o bastante em cada caso para demonstrar que essas tradições são flexíveis no tocante aos arranjos políticos com os quais podem ser tratados como compatíveis.

Finalmente, e o mais importante, tradições não são dadas de uma vez por todas; elas são continuamente inventadas e reinventadas (Hobsbawm e Ranger, 1983), um ponto enfatizado por Eickelman e Piscatori (1996) na sua análise do islamismo. De fato, as próprias análises da tradição confuciana citadas acima podem ser vistas como tentativas de inventar um confucionismo democrático. As culturas são feitas de tecido, mas o pano da cultura veste diferente nas mãos de diferentes alfaiates.

Essa visão foi vigorosamente contestada por Huntington (1993, p. 40). Ele começou observando que "os conceitos ocidentais são fundamentalmente diferentes daqueles que prevalecem em outras civilizações. As idéias ocidentais de individualismo, liberalismo, constitucionalismo, direitos humanos, igualdade, liberdade, império da lei, democracia, mercados livres, separação de Igreja e Estado, com freqüência têm pouca ressonância nas culturas islâmica, confuciana, japonesa, hindu, budista ou ortodoxa". E prossegue: "Os esforços ocidentais para propagar tais idéias acabam produzindo uma reação contra o 'imperialismo dos direitos humanos' e uma reafirmação de valores nativos, como se pode ver no apoio ao fundamentalismo religioso pelos mais jovem nas culturas não-

15 O método ex-post é ainda mais evidente em análises culturais do crescimento econômico. Veja-se Sen (1997).

16 Assim, Nathan e Shi encontram elementos de cultura democrática na China, enquanto Gibson, Dutch e Tedin os descobrem na Rússia. 
ocidentais". É difícil saber a base que permitiu que Huntington chegasse a essa conclusão. A maioria dos estudiosos do fundamentalismo religioso islâmico atribui o seu crescimento à deterioração das condições econômicas das massas urbanas, não ao “imperialismo dos direitos humanos'; a ascensão do fundamentalismo religioso está limitada a certos países dentro de certas áreas culturais, e é proeminente no país mais "ocidental" deles todos, os Estados Unidos. Sobretudo, as Cassandras do iminente Kulturkampf (também Fukuyama, 1995) fariam bem em olhar para trás antes de mergulhar à frente.

Ao contrário de Lipset, Almond e Verba ou Huntington (1984), que sustentaram que culturas totalizantes são menos favoráveis à democracia, o próprio Weber (em Gerth and Mills, 1958, pp. 337-8) pensava que o papel político das religiões instituídas depende dos seus interesses, não do seu conteúdo: “As posições empíricas amplamente variadas assumidas pelas religiões históricas perante a ação política foram determinadas pelo enlear-se das organizações religiosas em interesses de poder e lutas pelo poder ... pela utilidade das organizações religiosas para domesticar politicamente as massas e, especialmente, pela necessidade dos poderes em vigor da consagração religiosa da sua legitimidade". Num estudo exaustivo da emergência da Democracia Cristã européia, Kalyvas (1996) mostrou que a relação entre catolicismo e democracia seguia considerações estratégicas da Igreja Católica. Numa comparação audaz do fundamentalismo católico dos ultramontanos belgas no século XIX com o atual fundamentalismo islâmico argelino, Kalyvas (1997) concluiu que os resultados diferentes nesses dois países deviam-se à estrutura organizacional das respectivas religiões, mais do que ao seu conteúdo cultural. Linz e Stepan (1996, p. 453) chegaram à mesma conclusão com respeito aos casos recentes de democratização. Finalmente, Laitin (para o sumário mais recente, veja-se 1995) examinou em vários contextos o papel desempenhado por "empreendedores culturais" na dinâmica da mudança cultural, trazendo amplas evidências de que, enquanto conflitos sobre cultura podem ter resultados diferentes, eles dizem respeito a interesses e estratégias, e não a quaisquer conteúdos culturais dados primordialmente. Desse modo, o argumento de que inclinações antidemocráticas de "civilizações" são dadas de uma vez por todas bate de frente contra a experiência histórica. Retornando a Stuart Mill, que citamos acima: "As pessoas são mais facilmente induzidas a fazer, e fazem mais facilmente, o que já estão habituados; mas as pessoas também aprendem a fazer coisas novas para elas". 


\section{Evidências empíricas}

Quais são, então, as evidências empíricas relativas ao impacto de religiões sobre a dinâmica de regimes políticos? Há maior número de protestantes, e católicos, em democracias; muçulmanos e outros em ditaduras. Mas essa observação prima facie não basta para estabelecer um vínculo causal. Mesmo que admitamos que a democracia teve origem em países protestantes, uma vez estabelecida nesses países a questão é a de se saber se ela pode ser transplantada e sobreviver em outro lugar. Essa não é uma questão retórica, como Lipset (1994, p. 5), citando Lewis (1993) parece sugerir, mas uma questão empírica. $\mathrm{E}$ as evidências relevantes para esta questão não consistem em saber se em um determinado ponto no tempo, seja em 1950 ou 1990, mais países protestantes do que católicos ou muçulmanos eram democráticos, mas em se a democracia tem mais chances de emergir e manter-se em países protestantes.Em termos técnicos, isso significa é que as evidências relevantes são históricas e longitudinais, e não estáticas e sincrônicas.

Sendo assim, para testar a importância das religiões para a dinâmica de regimes políticos, calculamos o impacto de diferentes variáveis sobre as probabilidades de que a democracia se estabeleça e de que entre em colapso. Inicialmente, consideramos as três variáveis incluídas em nosso modelo não cultural: renda per capita, taxa de crescimento, e a taxa de rotatividade de chefes de governo acumulada ao longo da vida do regime ${ }^{17}$. Os resultados indicam que todas as variáveis são significativas estatisticamente. Quanto mais rica uma democracia, menos provável é que entre em colapso; enquanto as ditaduras mais ricas são um pouco mais propensas a entrar em colapso. Ambos os regimes têm chances bem menores de entrar em colapso se a sua economia cresceu no anterior. Democracias nas quais os chefes de governo mudam com mais freqüência têm uma chance ligeiramente maior de entrar em colapso, ao passo que ditaduras estão muito mais sujeitas a morrer nessas condições.

Quando adicionada a esse modelo não culturalista, a freqüência na população de cada país das três religiões para as quais temos dados católicos, protestantes e muçulmanos -não tem impacto algum na durabilidade da democracia e somente o catolicismo tem algum impacto - negativo - sobre a estabilidade de ditaduras. Além disso, quando outras variáveis são introduzidas na análise - o legado colonial, a heterogeneidade

17 A proporção de assentos legislativas ocupados pelo maior partido não é significativa na análise estatística. 
religiosa e étnica, ou a proporção de países no mundo que eram democracias durante o ano em questão - nenhuma das religiões importa para coisa alguma.

Pata testar a hipótese sobre o impacto da heterogeneidade cultural, usamos índices de fracionamento etnolinguístico e religioso ${ }^{18}$. O fracionamento etnolinguístico diminui a chance de sobrevivência de democracias, confirmando as expectativas baseadas no senso comum. O legado colonial de um país também torna a sobrevivência das ditaduras menos provável. Assim, tudo indica que a heterogeneidade etnolinguística afeta a estabilidade dos regimes e, de fato, seus efeitos desaparecem quando controlamos por instabilidade política passada. Logo, o argumento de que valores comuns são necessários para sustentar a democracia reduz-se à observação de que transições de regime são mais freqüentes em países marcados por heterogeneidade etnolinguística. Por sua vez, a heterogeneidade religiosa não tem efeito sobre a estabilidade de qualquer um dos regimes.

São evidências parcas, mas ocorre que culturas não se prestam a classificações simples. Disso decorre que a oportunidade para análises estatísticas é limitada. É óbvio que gostaríamos de poder classificar culturas como hierárquicas ou igualitárias, universalistas ou particularistas, religiosas ou seculares, consensuais ou conflituosas, e assim por diante. Mas as evidências que temos são insuficientes para afirmar-se que certas culturas são incompatíveis com a democracia. As culturas parecem ter pouco efeito sobre o estabelecimento da democracia, e nenhum sobre sua sobrevivência.

\section{REAVALIANDO O RELATIVISMO CULTURAL}

Há alguns anos, um de nós participou de uma reunião acerca de relações capital-trabalho na República da Coréia. À medida que a discussão progredia tornava-se claro para nós, ocidentais, que nossos interlocutores coreanos somente conseguiam imaginar dois estados do mundo: ou "harmonia e cooperação" ou o "vale tudo" da guerra aberta. A idéia de que conflitos possam ser regulados e portanto limitados parecia pura e simplesmente inconcebível para eles. Não fazia parte do seu repertório cultural.

18 Os índices de fracionamento medem a probabilidade de que dois indivíduos escolhidos aleatoriamente não pertençam ao mesmo grupo. O índice de fracionamento etnolinguístico é tomado de Eaterly e Levine (1997, da Internet). Seu conjunto de dados também contém índices que medem a porcentagem da população que não fala a língua oficial ou a mais amplamente usada. Esses dois índices não têm efeito na estabilidade do regime. 
Todos nós provavelmente tivemos uma experiência desse tipo em alguma ocasião. As culturas não são as mesmas, e o que as pessoas podem imaginar e estão prontas para fazer é moldado por pressupostos e hábitos culturais. No entanto, as culturas são também heterogêneas e maleáveis. Contamos aos coreanos que os europeus ocidentais também pensavam que sindicatos livres fossem incompatíveis com a democracia, e que, no entanto, nos últimos quarenta anos haviam gozado de relações trabalhistas civis, com os trabalhadores tendo o direito de associar-se e de fazer greve, com instituições de negociação coletiva minuciosamente reguladas, e com conflitos que terminavam em acordos pacíficos. E, embora nossos interlocutores tivessem dúvidas se um sistema como esse poderia funcionar no seu país, também sabiam que mais cedo ou mais tarde teriam que desenvolver tal sistema.

Assim, embora a intuição de que a cultura importa para a viabilidade de instituições democráticas tenha raízes na nossa experiência cotidiana, não nos deveria surpreender que as evidências em favor das concepções culturalistas sejam tão fracas. Comparações históricas de tradições culturais não conseguem especificar os mecanismos causais em que elementos culturais desempenhariam um papel na explicação. As mesmas questões são respondidas de forma diferentes de uma sociedade a outra, mas isto não é evidência suficiente para postular um papel causal para a cultura. Por sua vez, evidências estatísticas em favor de explicações não culturalistas da estabilidade de instituições democráticas parecem fortes. Logo, pouco ou nada há que nos pudesse levar a crer que obstáculos culturais à democracia sejam irremovíveis. A "hipótese de Lee", como Sen (1997) chamou os pronunciamentos de Lee Kuan Yew, não passa de fina camada de verniz sobre o seu desejo de manter-se no poder.

Suponhamos, contudo, que as evidências apontassem no outro sentido, e que a nossa revisão dos dados observados confirmasse a perspectiva culturalista. $\mathrm{O}$ argumento relativista padrão é que preferências culturais devem ser respeitadas porque são mantidas e expressas por pessoas que devemos respeitar (mesmo quando de fato são tipicamente expressas por aqueles que falam em seu nome, talvez com uma dose de interesse próprio). Mas a questão normativa é se preferências endógenas podem dar sustentação a julgamentos morais quando as pessoas em questão não estão simetricamente informadas. Sendo mais diretos: suponhamos que sem ter a experiência de conflitos regulados os coreanos justifiquem relações trabalhistas paternalistas invocando "harmonia e cooperação". Suponhamos, por outro lado, que, tendo instituído um sistema de negociação coletiva 
livre, eles descobrissem que não somente podem viver com esse sistema mas que o preferem à repressão aos trabalhadores. Deveríamos ter respeitado sua preferência por "harmonia e cooperação"?. Em termos mais gerais, deveríamos respeitar culturas antidemocráticas que sobrevivem em sociedades que jamais tiveram uma experiência de democracia?

Essa não é uma questão retórica, pois pessoas bem intencionadas e razoáveis podem discordar sobre a resposta em contextos específicos. Ela assinala, entretanto, uma fraqueza genérica do relativismo cultural.

\section{ADAM PRZEWORSKI é professor de Ciência Política na New York University. JOSÉ ANTONIO CHEIBUB é professor de Ciência Política na Yale University FERNANDO LIMONGI é professor de Ciência Política na Universidade de São Paulo.}

\section{REFERÊNCIAS BIBLIOGRÁFICAS}

ALVAREZ, M; CHEIBUB, J. A.; LIMONGI, F.; PRZEWORSKI, A. (1996). "Classifiyng Political Regimes". Journal of International Comparative Development, n. 31, pp. 3-36.

BARRY, B. (1978). Sociologists, Economists, and Democracy. University of Chicago Press.

COHEN, J. (1997). "Procedure and Substance in Deliberative Democracy". In J. Elster (ed.) Democratic Deliberation. Cambridge University Press.

COLLINI, S.; WINCH, D.; BURROW, J. (1983). That Noble Science of Politics. Cambridge University Press.

DAHL, R. (1956). A Preface do Democratic Theory. University of Chicago Press.

DUNN, J. (1992). "Conclusion". In J. Dunn (ed.). Democracy. The Unfinished Journey. Oxford University Press.

(1996). The History of Political Theory and Other Essays. Cambridge University Press.

ECKSTEIN, H. (1961). A Theory of Stable Democracy. Princeton University Center for International Studies.

ECKSTEIN, H.; GURR, T.R. (1975). Patterns of Inquiry. A Structural Basis for Political Inquiry. New York. Willey.

EICKELMAN, D. F.; PISCATORI, J. (1996). Muslim Politics. Princeton University Press.

EISENSTADT, S. N. (1968). "The Protestant Ethic Theses in the Frame of Sociological Theory and Weber's Work". In S. M. Eisenstadt (ed.) The Protestant Ethic and Modernization. A Comparative View, pp. 3-45. New York, Basic Books.

ESPOSITO, J. L.; VOLL, J. O. (1996). Islam and Democracy. Oxford University Press.

FUKUYAMA, F. (1995). "The Primacy of Culture". Journal of Democracy, n. 6.

GELLNER, E. (1991). "Civil Society in Historical Context". International Social Science Journal (UNESCO), n. 129, pp. 495-510.

GERTH, H; WRIGHT MILLS, C. , eds. (1958). From Max Weber. Essays in Sociology. Oxford University Press.

GIBSON, J. L.; DUCH, R. M.; TEDIN, K. L. (1992). "Democratic Values and the 
Transformation of the Soviet Union". Journal of Politics, n. 54.

GRANATO, J; INGLEHART, R.; LEBLANG, D. (1996). "Cultural Values, Stable Democracy, and Economic Development: a Reply". American Journal of Political Science, n. 40, pp. 680-696.

HOBSBAWM, E.; RANGER, T., eds. (1983). The Invention of Tradition. Cambridge University Press.

HUNTINGTON, S. P. (1993). Democracy's Third Wave. In L. Diamond and M. F. Plattner (ed.) The Global Resurgence of Democracy, pp. 3-25. Baltimore, John Hopkins Press.

IM, H. B. (1997). "The Compatibility of Confucianism and Democratic Civil Society in Korea". (IPSA, XVII World Congress, Korea).

INGLEHART, R. (1990). Culture Shift in Advanced Industrial Society. Princeton University Press.

JACKMAN, R. W.; MILLER, R. A. (1996). “A Renaissance of Political Culture?”. American Journal of Political Science, n. 40, pp. 632-659.

KALYVAS, S. M. (1996). The Rise of Christian Democracy in Europe. Ithaca, Cornell University Press.

(1997). "Religion and Modernization. Belgium and Algeria". (Washington, Annual Meeting, American Political Science Association).

LAITIN, D. (1995). "National Revivals and Violence". Archives Européennes de Sociologie, n. 36 , pp. 3-43.

LASWELL, H. D. (1946). Power and Personality. New York.

LEWIS, B. (1993). "Islam and Liberal Democracy". Atlantic Monthly, vol. 271, n.o 2, pp. 8998.

LINZ, J. J.; STEPAN, A. (1996). Problems of Democratic Transition and Consolidation. Baltimore, John Hopkins Press.

LIPSET, S. M. (1959). "Some Social Requisites of Democracy: Economic Development and Political Legitimacy". American Political Science Review, n. 53, pp. 69-105. - (1960). Political Man. GardenCity, New York, Doubleday.

(1994). "The Social Requisites of Democracy Revisited". American Sociological Review, n. 59, pp. 1-21.

MARAVALl, J. M. (1995). Democracía y Democratas. Estudio 1995/65. Madrid. Instituto Juan March de Estudios e Investigaciones.

MAZRUI, A. (1997). "Islamic and Western Values". Foreign Affairs, vol. 76, n. 5, pp. 118132.

MILL, J. S. (1991). Considerations on Representative Government. New York, Prometheus Books. [Original, 1861].

MONTESQUIEU (1995). De l'Esprit des Lois. Paris, Gallimard.

MULLER, E. N.; SELIGSON, M. A. (1994). "Civil Culture and Democracy: the Question of Causal Relationships". American Political Science Review, n. 88, pp. 653-652.

NATHAN, A. J.; SHI, T. (1993). "Cultural Requisites for Democracy in China. Findings from a Survey”. Dedalus, n. 122.

NEUBAUER, D. E. (1967). "Some Conditions of Democracy". American Political Science Review, n. 61, pp. 1002-1009.

PRZEWORSKI, A. (1991). Democracy and the Market. Cambridge University Press.

PRZEWORSKI, A. (1997). "Why Democracy Survives in Affluent Countries". (Annual Meeting, American Political Science Association).

PRZEWORSKI, A.; ALVAREZ, M.; CHEIBUB, J. A.; LIMONGI, F. (1996). "What Makes Democracy Endure?". Journal of Democracy, vol. 7, n. 1, pp. 39-56.

PRZEWORSKI, A.; ALVAREZ, M.; CHEIBUB, J. A.; LIMONGI, F. (1996). Democracy and Development. Political Institutions and Economic Performance in the World, 1950-1990. Cambridge University Press. 
PRZEWORSKI, A.; LIMONGI, F. (1997). "Modernization: Theories and Facts". World Politics, n. 49, pp. 155-184.

RAWLS, J. (1993). "The Domain of the Political and Overlapping Consensus". In D. Copp; J. Hampton; J. E. Roemer (ed.) The Idea of Democracy. Cambridge University Press.

ROUSSEAU, J.-J. (1985). The Government of Poland. Indianapolis, Hacket. [Original, 1771].

SCHMITTER, P. C.; KARL, T. L. (1991). "Whar Democracy Is and Is Not". Journal of Democracy, n. 2, pp. 75-88.

SEN, A. (1997). Culture and Development. Global Perspectives and Constructive Criticism. (Paper prepared for UNESCO's World Culture Report 1998).

TOCQUEVILlE, A. de (1961). De la Democratie en Amerique. Paris, Gallimard. [Original, $1835,1840]$.

VERSINI, L. (19950. "Introduction”. In Montesquieu, De l'Esprit des Lois. Paris, Gallimard.

WEBER, M. (1958). The Protestant Ethic and the Spirit of Capitalism. New York, Scribner. [ Original 1904-1905].

WEINGAST, B. R. (19970. "Political Foundations of Democracy and the Rule of Law". American Political Science Review, n. 91, pp. 245-263.

WIARDA, H. (1981). Corporatism and National Development in Latin America. Boulder, Westview.

WIARDA, H. (1989). "The Dominican Republic. Mirror Legacies of Democracy and Authoritarianism". In 1. Diamond, J. L. Linz, S. M. Lipset (ed.) Democracy and Developing Countries: Latin America. Boulder, Lynne Riener Publishers.

WIATR, J. J. (1979). "The Civic Culture from a Marxist Sociological Perspective". In G. A. Almond and S. Verba (ed.) The Civic Culture Revisited, pp. 103-123. Boston, Little, Brown.

WINCH, D. (1978). Adam Smith's Politics: an Essay in Historiographic Revision. Cambridge University Press. 


\title{
RESUMOS/ABSTRACTS
}

\section{DEMOCRACIA E CULTURA: UMA VISÃO NÃO CULTURALISTA}

\author{
ADAM PRZEWORSKI \\ JOSÉ ANTONIO CHEIBUB \\ FERNANDO LIMONGI
}

Os autores sustentam que fatores econômicos e institucionais são suficientes para gerar uma explicação convincente da dinâmica das democracias sem que seja necessário recorrer à cultura. Concluem que, embora possa haver boas razões para esperar que culturas importem, o material empírico disponível provê pouco apoio para a concepção de que a democracia requer uma cultura democrática.

Palavras-chave: Democracia; cultura; culturalismo.

\section{DEMOCRACY AND CULTURE: A NON-CULTURALIST VIEW}

The authors hold that economic and institutional factors are sufficient to generate a convincing explanation of the dynamic of democracies without any resource to culture. Their conclusion is that, while there may be good reasons to expect that culture matters, the available empirical evidence provides little support for the view that democracy requires a democratic culture.

Keywords: Democracy; culture; culturalism. 